\title{
ANADOLU'DA BORSA VE ENFLASYONUN İLK ŞEKILLERI
}

Hüseyin SEVER

Borsa: Arz ve talebin belli zaman ve yerde karşılaşmasına ve alışverişin daha büyük ölçülerde yapılmasına imkân veren bir kuruluştur. Borsa, aynı zamanda, devletin müsaade ve kotrolü altında, fiatların daha normal ve geniş oluşmasını sağlayan bir pazardır.

Borsa, gerçekte hemen hemen insan ile doğmuş ve daha doğrusu, insan ihtiyaçlarının aynî mübadelesi, yâni eşyanın elden ele geçmesi ihtiyacı ile, kendiğilinden teşekkül etmiş temeli hemen hemen, insanlarda bir meskene sahip olma fikrinden önce atılmış bir müessesedir. Borsanın yeni olan bir tarafı varsa, o da ismidir. Íktisadî münâsebetlerin tarihi gelişimi içinde bazen pazar ve panayır gibi geçici veya esnaf dernekleri ve loncalar gibi, dâimî şekil almış, bazen de aynı ticaret ve sanatla uğraşanların hep birlikte iş merkezi yaptıkları mahalle veya sokak şekline girmiş, fakat bütün bunlarla aynı ihtiyacın sağlanmasına çalışılmıştır.

Borsalar, yaptıkları işlemlere ve bu işlemlerin konusunu oluşturan maddelere göre: "Esham ve tahvilât, Kambiyo ve para, Ticaret, Emtia, Zâhire ve Nakliyat" borsaları diye adlandırılırlar.

Resmî ve serbest borsalarda ne sebeple olursa olsun, işlem görmeyen döviz, emtia ve menkul kıymetlerin gizli bir şekilde alınıp satıldığı piyasa veya bu tür işlemlere ise "KARABORSA" adı verilmektedir. Karaborsalarda yapılan işlemleri, devlet gerek gördükçe cezaî hükümlere tâbi tutar'.

Enflâsyon: Ekonomide fiyatların genel seviyesinin sürekli olarak yükselmesi, câri fiyat seviyesinde toplam talebin, toplam arzdan fazla olmasıdır. Piyasadaki para miktarının dengeyi bozacak ölçüde artması, veyahut da mal arzının artan talebi karşılayamaması ve neticede piyasada fiyatların yükselerek para kıymetinin düşmesi, enflâsyonun en bâriz belirtisidir. Enflâsyonun bir adı da "para hastalığı"dır.

1. Bu konuda geniş bilgi için bkz. Türk Ansiklopedisi, Cilt: VII, s.341-348. 
Enflâsyon, ithal malları fiyatlarının artışı, kötü hava şartları sonucu tarım ürünlerinin üretiminin azalışı veya ücret gibi mâliyet unsurlarından birinin yükselişi sebebiyle, fiyatların genel seviyesinin artmasıdır. Enflâsyonun bir diğer sebebi de yatırımların tasarruflardan fazla olan kısmı, piyasaya karşılıksız para sürülerek karşılanıyorsa, bu da enflâsyona yol açar.

Enflâsyonla mücadele etmek için aşağıdaki tedbirleri almak gerekir: düşürülür.

1. Tedâvüldeki para miktarı azaltılarak, fertlerin satın alma güçleri

2. Fertlerin tasarrufa yönelmesi için birtakım teşvik tedbirleri alınır.

3. Taksitli satışlar sınırlandırılır.

4. Bazı malların satışlarından narh uygulanır.

5. Tüketime yönelik krediler azaltılır.

6. Yokluğu hissedilen malların yurtdışndan alınması sağlanır.

7. En etkili tedbir olarak da, ekonomide üretimi arturıcı tedbirlere başvurulur ${ }^{2}$.

Altın, gümüş ve bakır gibi zengin maden kaynaklarına sahip olan Anadolu'da, M.Ö. III. bin yıllarında, adı geçen bu madenlerin işletilmekte olması ve ziraat tekniğinin son derece ilerlemesi yüzünden, Güneydoğu Anadolu'da ve kuzey Mezopotamya sınırları içinde yaşayan Asurlu tuiccarların ilgisini çekmiştir. Bu sebeplerden dolayı Asurlu tüccarlar M.Ö. 1970-1750 tarihleri arasında en az 200 yıllık bir zamanda, Anadolu'ya gelerek, Asur Ticaret Kolonileri Çağını kurmuşlardır ${ }^{3}$.

Bugün artık sayıları 150'leri bulan ticaret merkezleri kurmus olan Asurlu tüccarların idâre merkezi veya başkentleri durumundaki Kültepe (=Kaniš)'de yapılmı̧ olan kazılarda, tüccarların ticâret faaliyetlerini anlatan ve bugüne kadar gün ışığına çıkarılan yazılı vesikaların sayıları onsekizbine ulaşmıştır.

Yukarıda bahsi geçen belgelerden öğrendiğimize göre, Asurlu tüccarlar M.Ö. II. binli yılların başlarından itibaren, "kara eşek kervanları"

2. Bkz. Türk Ansiklopedisi, Cilt:15, s.207-208.

3. H. Sever, Yeni Belgelerin Işığında Asur Ticaret Kotonileri Çağı Kronolojisinin Yeniden Değerlendirilmesi, (Uluslararası I. Hititoloji Kongresi, 19-21 Temmuz-1990-ÇORUM), s. 1.34-139. 
ile kalay, Anadolu'daki saraylara ve yerli halka ipekli kumaşlar, süs eşyaları ve parfümler getirmişlerdir. Tüccarlar, getirdikleri bu eşyaların karşılığında Anadolu'dan bol miktarda altın, gümüş, bakır ve kıymetli taşlan Asur'a götürmüşlerdir.

Asurlu tüccarlar aynı zamanda, Anadolu'da da çeşitli eşya îmâlinde kullanılan bakırı, bir şehirden diğerine naklederek, iç ticaretten ve yerli (=Anadolulu) halka \%240'lara kadar ulaşan faizle borç para vererek, büyük kârlar da elde etmişlerdiŕ.

Anadolu'da kalay mâdeni çok az bulunduğundan, tüccarlar Asur pazarlarından ucuza satın aldıkları kalayı, yerli (=Anadolulu) halka oldukça pahalıya satıyorlardı. Kārum ve wabartum adı verilen bu pazarlarda kalayın yerli halka satışı gümüşe nisbetle $1 / 5,5$ veya $1 / 10$ değerlerine göre yapilmaktayd.

Yerli krallarca, tüccarların Anadolu'ya getirdikleri diğer ithal mallara $\% 5$ nisbetinde gümrük vergisi uygulandığı halde, ihtiyaca binâen, alaşıma hazır durumdaki kalaya ise, \%2 veya \%3 oranında değişmekte olan gümrük vergisi alınmaktaydı.

Kalaya bu kadar düşük bir ithal vergisi uygulayan mahallî idâreciler bununla da yetinmeyip, bu mâdenin Anadolu dişına çıkışını da yasaklamişlardır.

Kalay, tekstil ticareti ve diğer faaliyetlerden büyük kârlar sağlayan Asurlu tüccarlar Anadolu'da bir müddet kaldıktan sonra kazançlarını altın, gümüş, bakır ve kıymetli taşlara çevirip, Asur'a dönüyorlar, giden bu tüccarların yerlerine de Asur'dan Anadolu'ya başkaları geliyorlardıs.

Uzubiškum' adlı Asurlu bir tüccarın, Uşur-ša-Ištar adlı diğer bir tüccara yazmış olduğu, Kt.n/k-562 kazı envanter numaralı bu mektupta: Kalay, kurların (fiyatların) düşik olmasından dolayı, onun kalayının hâlâ bekletilmekte olduğunu bildiren ve ondan bakır madeninin verilmesine karşılık, kendi senedinin gönderilmesi hususundaki isteğini belirtmektedir:

4. E. Bilgiç, Asurca Vesikalara Göre Etilerden Önce Anadolu'da Mâden Ekonomisi, Sümeroloji Araşırımaları I (A.Ü.D.T.C.F., Sümeroloji Ėnstitüsii Neşriyat11, 1940-1941).

5. E. Bilgiç, Kapadokya Tablełlerine Göre Anadolu Kavimleri Üzerinde Araşırmalar. (A.Ü.D.T.C.I.D. II, 35. Ankara-1943).

E. Bilgị̧, Çivi Yảıh Ilukukîtłklisâdî Kaynaklar, Mâhiyeti ve Muhtevâları. (Belleten XI, 44, s.571-602. Ankara-1947).

E. Bilgiç, M.Ö. 2000 Yıllarında Anadolu Kavinleri. (III. Türk Tarih Kurumu Kongresi, Tebliğler: 9. seri, 3, s.379-386. Ankara-1948). 
Öy. 1. a-na Ú-șú-ur-ša-Ištar

qi-bi-ma um-ma

Ú-zu-bi 4 -iš-ku-um-ma

a-šu-mì AN.NA ${ }^{b i}$-kà

5. ̌a ta-áš-pu-ra-ni

ší-mì-im AN.NA

ba-tí-iq AN.NA-kà

K. a-dí-ni i-ba-ší

Ay. a-dí-ni tup-pí

10. a-dí ma-la ù

ší-ni-šu áš-pu-ra-<ku>-um

a-hiria-ta

URUDU ša ta-da-nim

dí-in țup-pì

15. šé-șí-ma

$a-s ̌ a r ~ e-z a-b i_{4}-i m$

K. e-zi-ib-šu-nu

(1-3) Uzubiškum, Ușur-ša-Ištar'a şöyle söylüyor: (4-8) Senin bana yazdığın kalayın hakkındaki yazına gelince, burada kalayın fiyatı (kur fiyatı) düşüktür. Senin kalayın şimdilik (burada) duruyor (9-11). Zaten ben (de) sana bir-iki defa mektup yazmıştım. (12-14) Lütfen sen bakırları vereceksen ver. (14-17) Senedini (=metin: tabletini) çıkarttırıp, (bakırları) birakılacak yere birakıver.

Ah-šllim ve Ikūppia adlarındaki Asurlu tüccarların meslekdaşları olan ve yine Asurlu tüccar, Ușur-ša-Ištar'a gönderdikleri Kt.n/k-606 kazı envanter numaralı mektupta: Atata ve Ašssur-imitti'nin Hurașānum adına herhangi birşey söylerlerse ve gümüş iyi fiyata satılıyorsa (=metin: gidiyorsa), kendilerine haber vermesini istemektedirler. Bunun için de Ašsurtâb (=DUGG)'ı göndererek, Aššrur-imitti ve Atata isimli şahıslarla beraber meseleyi hallettireceklerini belirtmektedirler: Konumuzla ilgili olan 9-16. satırlarını aşağıya alıyoruz:

Öy. 9. ک̌um-ma a-ma-kam

10. a-ší-ma-at KÙ.BABBAR

i-ma-gu-ru-ni-a-tí 


\author{
ú-za-ni pè-tí-a \\ K A-š̀ur-DÙG \\ lu ni-iţ-ru-da-ma
}

Ay. 15. a-wa-tim

li-mu-ru

"(9-16) Eğer orada (aynı zamanda) gümüşün fiyatlarına bizim için muvafakat ediyorlarsa (bizim için uygun görüyorlarsa), bizi (bu konuda) uyar(=metin: kulağımızı aç) ki, (oraya) Aššur-tâb-ı gönderelim (=metin: sevkedelim) ve onlar (kendi aralarında) meseleyi halletsinler."

Yine Kt. n/k-556 kazı envanter numaralı ve Illabrat-bāni tarafından, Hanana ve Uşur-ša-Ištar'a yazılmış olan ticari mektubun 13-15. satırlarında bakırının gümüşe çevrilmesini istemektedir:
13. URUDU [ku-nu]-ki-a šu-ma a-na
14. KÌ.BABBAR [dí-] na-šu-ma a-na
15. Ta-ri-iš-ma-tim dí-na-šu-ma

"(13-15) Benim mühürümle (mühürlenmiş olarak) gelen bakırı eğer paraya (gümüşe) çevirirseniz onu (bayan) Tariš-mātum'a veriniz."

Kt.n/k-576 envanter numaralı diğer bir vesikada ise, Illabratbāni'nin, Sāsia, Hanana ve Ușur-Ša-Ištar'a yazmış olduğu, fakat esas muhatap olarak da Uşur-ša-Ištar'a, daha önce kendisine bırakılan iki ayrı cins altınin 1 šeqelini 5 1/2'şer ऊeqel gümüş ile değiştirdiğini zikretmektedir.

Ayrıca, metnimizde geçmekte olan "kuburSinnum" ve normal altının 5 1/2'şer šeqel gümüşe eşdeğerde olması, bahsedilen altın cinsinin düşük kalitede olduğu kanaatını da uyandırmaktadır.

Konunun önemi bakımından bu vesikayı buraya aynen almayı uygun buluyoruz:

Öy. 1. a-na Sá-sí-a Ha-na-na

ù Ú-șú-ur-కa-Ǐ̌tar qí-bi-ma

um-ma "NIN.ŠUBUR-ba-ni-ma

15 GÍN KÙ.GI ku-bur-Sí-num

5. 7 GIN KÙ.GI ša áb-ni-šu

a-na Ú-șur-ša-Ištar e-zi-ib-ma 
ù té-er-tù-šu i-li-kam

um-ma Su-ut-ma 5 1/2 GíN.TA

KÙ.GI-kà a-dí-in-ma

10. 2 ma-na 1 GÍN KÙ.BABBAR al-qí

ŠÀ 15 GÍN a-na Ša ki-ma

¿IM.GAL áŠ-qúl Ší-tí KÙ.BABBAR

K. $\quad 12 / 3$ ma-na 6 GíN i-ba-ší

Ay. 16 ma-na URUDU SIG,

15. ša Ta-ri-tar ku-nu-ki-a

Ki-in-wa-nu-wa ub-lá-ku-nu-tí

15 GÍN KÙ.BABBAR şa-ru-pá-am

ù 10 ma-na URUDU SIG s ku-nu-ki-a

A-Sur-i-mì-tí kà-șa-ar

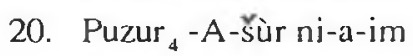

na-áš-a-ku-nu-tí a-ḩu-a

be-lu a a-tù-nu URUDU SIG $_{5}$

a-na KÙ.BABBAR ta-e-ra-ma

$15 / 6$ ma-na KÙ.BABBAR KI Puzur ${ }_{4}$-A-צur

25. ni-a-im a-șí-ib-tim

al-qí tup-pì am-ra-ma

K. KÙ.BABBAR ù șí-ba-sú

Ša-bi ${ }_{4}$-a-'̌su-ma tup-pì sé-şí-a-ma

sK. Šé-bi ${ }_{4}-$ lá-nim šu-ma KÙ.BABBAR ir-dí-a-ă

30. ku-sí-a-tim కa Ma-am-ma

$\mathrm{SIG}_{5}{ }^{\text {limi }}$ Ša-ma-ma sé-bi ${ }_{4}$-lá-nim

be-lu-a a-tù-nu a-wi-lam sa-bia ${ }_{4}^{-a}$

"( 1-3) Sāsia, Hanana ve Uşur-ša-IŠtar'a, "İllabrat-bāni şöyle söylüyor: (4-7) Onun tartısı ile 15 šeqel kuburšinnum alını, 7 šeqel (normal) altını Ușur-కa-Ištar'a bırakmıştım, onun haberi bana ulaştı. (8-10) O(Uşur-šaIštar), şöyle diyordu: Senin altının $51 / 2$ 'şer Ǩeqel gümüşüzerinden verdim ve 2 mina 1 Seçel gümüş aldım (11-12). Bunların içinden 15 šeqel 
gümüşü dAdad-rabi'nin vekiline verdim (=metin: tarttım). (12-13) Bakiye $12 / 3$ mina 6 కeqel gümüş durmakta(dır). (14-16) 16 mina iyi cins Tarittar bakırırını, benim mühürümle Kinwanuwa size getirmektedir. (17-21) 15 కeqel tasfiye edilmiş gümüşü ve 10 mina iyi cins bakırı bizim PuzurAššrun eşek yükleyici ve sürücüsü (olan) Aššrur-imitti, benim mühürümle size getirmektedir. (21-26) Sizlerden tekrar tekrar istirham ediyorum (=metin: Sizler benim kardeşlerim ve efendilerimsiniz). Lütfen iyi cins bakırı gümüşe çeviriniz. 1 5/6 mina gümüşü bizim Puzur-Aššur'dan faize karşılık olmak üzere aldım. (26-28) Senedimi görüp parayı ve faizinin tamamın bana ödeyiniz. (28-29) Senedimi çıkarttırıp bana gönderiniz. (29-31) Eğer onlar ....sevkettilerse Mamma'nın iyi cins kusitum kumaşlarını satın alıp, bana gönderiniz. (32) Sizlerden istirham ediyorum lütfen (=metin: Sizler benim efendilerimsiniz) adamı tatmin ediniz.

Hurasānum adlı bir tüccarın meslekdaşı Aššur-imitti'ye yazmış olduğu Kt.n/k-1689 kazı envanter numaralı mektupta, maden ticareti konusu ele alınmakta olup, "sikkatum" adı verilen üst düzeylerdeki bir devlet memurunun bu işlere görevlendirildiğini zikretmektedir. İstenilen bakırın mevcut olduğunu, fakat, altın ve gümüşün ise olmadığını, sikkatum geri dönünce (gelince) istenilen altını alıp, postacı ile göndereceğini belirtmektedir:

Öy. 1. a-na A-šur-i-mì-tí

qí-bi-ma um-ma

Huu-ra-șa-num-ma

Ší-mì ta-dí-in-ma

5. URUDU i-ba-Ší sí-kà-tum

ú-şa-ma i-na ma-ḩi-ri-im

KÙ.BABBAR ù KÙ.Gl lá-šu

a-bi a-ta a-క̌a-me-ma

lá ú-కé-bi-lá-ku-ni

10. li-ba-kà lá tù-[lá]-ma-an

a-dí lá tù-a-ar

e-li-tim mi-ma

K. lá ǔ-šé-ba-lá-[kum]

Ay. sí-kà-tum a-na

15. $10 u_{4}$-me-e i-tù-ra-nim-ma

KÙ.GI a-ša-a-ma 
KI a-li-ki ŭ-క̌é-ba-lá-kum

ki-ma a-na-kam AN.NA

ša-bu-ni 1 GÚ 20 ma-na

20. AN.NA ǔ 60 TÚGuls

a-na Pu-ru-uš-ha-tim

Ú-zu-bi a -iš-kà-am

ú-క̌é-bi ${ }_{4}-\mathrm{il}_{5}$ a-ša-me-ma

ma-ku-ḩu i-na Pu-ru-<uš>-ḩa-tim

25. wa-qar కa 10 ma-na

K.

KÙ.BABBAR ร̌a-a-ma

Yé-bi-lá-ma

sK. KÙ.BABBAR 1 ma-na ú 2 ma-na

ku-a-tili-li-a-kum

"(1-3) Aššur-imitti'ye, Hurașānum şöyle söylüyor: (4-7) Sen bedelini verdin ve bakır da mevcuttur. Sikkatum geriye Anadolu'ya dönecek (=metin: çıkacak). Fakat pazarda gümüş ve altın yoktur. (8-10) Sen benim büyüguümsün. İşittim ki, sana göndermemişler. (Bundan dolayı) kalbin kırılmasın. (11-13) Kervanın geri dönmemiş olması yüzünden sana birşey gönderemiyorum. (14-15) Sikkatum (memuru) 10 güne kadar buraya dönecek ve (16-17) altını satın alıp, postacı ile sana göndereceğim. (18-23) Burada yeteri kadar kalay mevcut oldugundan, 1 biltum, 20 mina kalayı ve 60 top kumaşı Uzubiškum ile Purušhthattum'a gönderdim. Yine işittim ki, (24-27) Purušḩattum'da "makuhu" cinsi kumaş pahalıdır. 10 mina gümüşlük satın al ve buraya gönder.(28-29) 1 veya 2 mina gümüşü de sana getirsin (=metin: yukarıya, Anadolu'ya çıkarsın).

Metnimizin 14. satırında .geçmekte olan "sikkatum" memuru, AKT I, No: 78'de, 15-16. satırlarında geçmekte olan "ra-bi sí-ki-tim" veya "ra-bi sí-kà-tim" memuriyet unvanı yanında, Kapadokya metinlerinde bizim metnimizde de olduğu gibi, yalnız başına sí-kà-tum/tim yazılışıyla bu meslek sınıfının normal mensuplarından da bahsedilmektedir. rabi sikkitim: Garelli (AC, s.217) ve von Soden (AHw, s.1042 a) tarafından "maden ticaretinin gözetiminden sorumlu (?) bir memur "anlamında alınmakla beraber, umumiyetle "yüksek rütbeli bir memur" veya "yüksek rütbeli bir komutan" (Landsberger, Ar.Or.XVIII, 1-2, s.331, not.445; Larsen, OACC, s.155) olabileceği zikredilmektedir ${ }^{6}$.

6. AKT I, s.95-98, No.78. 
Bundan önceki, Kt.n/k-1689 kazı envanter numaralı belgede geçen şahıslar arasında vukubulan, Kt.n/k-1340 kazı envanter numaralı ve yine Hurașānum'un Aššur-imitti adlı tüccar meslekdaşına yazmış olduğu bu mektupta: Hurașānum'un, Aššur-imitti'ye olan borçlarına karşılık olarak, değişik miktarlardaki altınları gönderdiğini zikretmekte, tanrı Ašsur'un ve tanrı Ištar'ın da bu ödeme olayına şahit olduklarından bahisle; Ayrıca, borsa muâmeleleri neticesinden dolayı gümüş fiatlarımn arttığından ve bu yüzden de altını daha pahalıya almak zorunda kaldığından üzüntülerini belirtmektedir:

$$
\begin{aligned}
& \text { Ò. a-na A-šur-i-mì-tí } \\
& \text { qí-bi-ma um-ma } \\
& \text { Hu-ra-șa-nu-ma } \\
& 10 \text { ma-na KÙ.BABBAR ù }
\end{aligned}
$$

25. i s $_{5}$ qí šu-ma la il ${ }_{5}$-qí 
s.K. té-er-tù-ร̌u li-li-kam-ma

a-Šar e-zi-bu

28. la-al-qí

Öy. (1-3) Aššur-imitti'ye, Hurașānum şöyle söylüyor: (4-13) 10 mina gümüşü ve 1 mina altını Ỉli-turam sana getirdi. Benim mühürüm ile mühürlenmiş olan 2 mina altını, Ușur-ša-İštar sana getirmektedir. Benim borcuma karşılık (borcuma âit) olan bütün bu şeylere (ödemelerime), tanrı A Šsur ve tanrı İ̌tar şahittirler (\$̧ahit olsunlar). (14-16) Uşur-ša-İštar bana geldiği zaman gümüşün fiatı yüksekti ve (17-19) bu yüzden $221 / 2$ SE altını sekizer ( $8^{\circ}$ er) šeqel üzerinden ( 1 seqel altını 8 Seqel gümüş karşılığında) almaya mecbur oldum. Ben diyorum ki; (20-25) o, bakır başkasına (yabancıya) gitmesin. Sen orada onun hakkında soruşturma yap (metin: orada onu soruştur). Senin 5 top "kutānum" kumaşını Tuhpia şehrinde (oturan) Būșia satın aldı. Eğer o almadı ise, (26-28) bu husustaki haberi bana gelsin ki, onun bıraktığı yerden (onun bıraktıklarını) ben, bakırı satın alayım (metin: onu ben satın alayım).

\section{FÍLOLOJIKK İZAHLAR}

1. Kt.n/k-562 numaralı (AKT II, 36 numaralı metin) metnimizin 6-7. satırlarında (s.5) ve bunu teyid eder mahiyetteki Kt.n/k-131 kazı envanter numaralı başka bir metnin 14-15. satırlarında da geçen "šiman hatāıım" "=" fiatı düşük olmak/fiatın düşük olması" anlamı ile ilgili olarak (bkz. AHw, s.114 a) şu ifadeler geçmektedir:

a) $a A$ - (Geld) abzichen: 1 Mine Silber la i-ba-ta-qám: CCT II, 3, 22; bu-tù-uq IV, 40 a, 19; ib-tù-qám-ma BIN IV, 146, 13; s.6, 29, $11 ; 176,21 \mathrm{f}$.

b) aA-inl Kurs heruntergehen (?)= Kurun aşağı düşmesi. TC I, 2630; s.2, 3, 19; BIN IV, 19, 18: für mein Zinn je 6 Sekel la ta-bata-qám.

c) aA-St. batiq (Preis, Kurs) ist zu niedrig.

Ayrıca bkz. CAD B, 163 b: 5-b: to become cheap: inūmī [kas]pū iba-tù-qú-ni [క̌u]ātimma i-ba-tù-qú-šu-um; if the silver goes down in price, it should go down only at his expense BIN VI, $176021 \mathrm{f}$;; see J. Lewy, Or.NS XV, 395; sa 6 GÍN ana anniki-ia la i-ba-tù-qú= they must not go below the price of six shekels (of silver) for my tin BIN IV, 19, 18; ana anniki-ia 6 GÍN.TA la ta-ba-ta-qám= you must not sell (lit.: be) cheaper thon six shekels (of tin) per shekels (of silver) with regard to my tin TCL IV, 26, 30, cf. ana annikim 6 GíN.TA ula i-ba-ta-aq TCL XIV, 3: 19 (all OA); B. Kienast, AT- 
HE 65, 8,8: ku-ru-um ba-ti-iq= ist das Kurrum billig? Ayrica, altnot 8'de: Zu batāqum=, niedrig (im Kurs) sein, billig sein. see A.L. Oppenheim, AfO XII, 348.

2. Kt.n/k-1340 numaralı metnimizin 4-13. satırlarında bahsi geçen Huraşānum'un, Aššur-imitti'ye olan borçlarını ödediğine dâir tanrıların şahit olarak gösterilmesi ile ilgili olarak kullanılmış "lițtula" formu, "națalu(m)= (Augen) aufheben; schauen: AHw.s.766 v.d. als Eidzeugen= "şahit olarak/şahit sıfatı ile"; aA- "Aššur u... li-țù-la "; ATHE 27, satır: 33-38: (33) Aš-šùr li-țù-ul a-na (34) 30 ma-na kaspi ${ }^{p}$-a ma-la u $u_{4}$-mu (35) e-tí-qú-ni 1 1/2 GÍN.TA șí-ib-tam (36) na I ma-na-im la a-ša-me-ú-kà (37) ù a-Ša-pa-ra-ma (38) ú-qa-lu-lukà. Yine ATHE 38, st.12-13'de: (12) Ašur u ilu lu a-hu-tim (13) lițù-la. Ayrıca bkz. Hirsch, AfO Beih.13, 6 f.; B. Landsberger-K. Balkan, Asur Kralı İrišum'un Kültepe'de 1948'de Bulunan Kitabesi, Belleten XIV, 54, s.258: Tanrı Aššrur, tanrı Adad ve koruma tanrısına hitap şekli (IAK, s.30-46): IV. Puzur-Aššur'dan Enlil-nirāri'ye kadar takdis formüllerinde, tannı Aššur, tanıı Adad ve diğer yardımcı kaydedilmişlerdir:

1) Sayfa 42, 27: Ǎšsur Adad ù "Bēlu-LUGAL.

2) Sayfa 44, 4, 11: Aššur Adad ù 'Ǐstar-kudnittum.

M.Ö. 1300'lerden sonra yalnız tannı A ̌̌šrur ve mâbedi yenilenen tanrıya bu şekilde hitap edilmiştir.

Yine CAD N, II, s. 122, 1-c maddesinde: to witness: A-šur u $\mathrm{il}_{5}$-kà li-ţù-la may Aššur and your god be witnesses. HUCA 4o-41, 61 f. L 29592: 14 f., cf. Aššur u ilūni li-țù-lu. HUCA 32, 47 n.101, Aššur u il ebarūtim li-țù-la, Kienast, ATHE 38, 13; A šsur ilki u abini li-ţù-la Jankowska, KTK 18: y+11; Aššur u İštar-ZA-AD li-țù-la VAT 9301: 4, also Aššur lițù-ul ICK I, 177: 28, and passim in OA; I In personal names: İ-lí-li-tù-ul RA 54, 29, No: 35, 3, Li-ṭul-DINGIR LIH 17: 13, DINGIR-li-tù-ul ÜET 5, 136: 24, 561 ii 14, 697: 6, Sin-li-țù-ul Birot Tablettes 11: 25, but Sinlu-uț-tù-ul ibid.seal; I-na-att-ța-al-DIN[GI]R Kraus, AbB I, 67: 6 (all OB), see Stamm Namengebung 165; uncert.: Ut-li-Ǐstar ARM 6, 14: 11. 